\title{
Characterization of Granule Structure and Packed Bed Properties of Iron Ore Sinter Feeds that Contain Concentrate
}

\author{
Mingxi ZHOU, ${ }^{1)} \mathrm{Hao} Z \mathrm{ZHOU},{ }^{1) *}$ Damien Paul O'DEA, ${ }^{2)}$ Benjamin George ELLIS, ${ }^{2)}$ Tom HONEYANDS ${ }^{3)}$ \\ and Xutao GUO'1)
}

1) State Key Laboratory of Clean Energy Utilization, Institute for Thermal Power Engineering, Zhejiang University, Hangzhou, 310027 P.R. China. $\quad$ 2) BHP Billiton, Brisbane, Qld 4000 Australia.

The University of Newcastle, Callaghan, NSW 2308 Australia.

3) Centre for Ironmaking Materials Research,

(Received on December 21, 2016; accepted on February 20, 2017; J-STAGE Advance published date:

April 15, 2017)

\begin{abstract}
Several sinter plants in China are still using significant proportions of local magnetite concentrate in the sinter blend based on supply proximity. However the overall trend is that concentrates are being replaced by more cost effective sinter fines. The fine size of concentrates results in additional challenges for sintering. In this study, granulation and packing experiments were conducted to investigate the influence of concentrate addition level on granule structure and green bed properties under a wide range of moisture and hydrated lime dosage levels. Provided sufficient water is added during granulation, the existence of micro-particles including concentrate and hydrated lime favours granule growth and increases the mass ratio of adhering layer to nuclei. However, at the same moisture and hydrated lime content, the introduction of more concentrate decreases the bed voidage remarkably since the thicker and weaker adhering layer deforms during dynamic packing. Compared to the $100 \%$ sinter fines base blend, introducing concentrate has a negative effect on bed permeability and therefore sinter productivity. For the 10\% and 30\% concentrate blends tested, increasing hydrated lime from 0 wt $\%$ to 4 wt\% could improve the green bed permeability in JPU from 53.0 to 65.8 and 39.4 to 60.8 respectively. Based on the experimental results, a semi-empirical green bed voidage model was improved in two aspects. One is applying a one dimensional packing algorithm to get the ideal porosity of dry coarse particles utilising size distribution data rather than the simple log-normal deviation parameter. The other is to add a probability term considering the deformation of granules only happens to the adhering layer. Combined with the widely accepted population balance granulation model developed by Litster, the improved model can give more accurate predicted voidage values for modeling the sintering process and optimizing actual production from the properties of raw materials and moisture content.
\end{abstract}

KEY WORDS: granule structure; voidage; bed permeability; iron ore sintering; concentrate.

\section{Introduction}

The iron ore sintering process produces the main iron-bearing material for blast furnaces in most integrated steel mills. This important pre-processing technology can be viewed as a two-stage process of cold packed bed preparation followed by hot bed transformation. For the cold bed preparation, raw materials including iron ores, fluxes, fuel and return fines are blended and granulated primarily to produce granules with proper mean size, size distribution and strength. These granules are then charged onto the sinter strand to form a packed bed with optimum permeability. As the properties of the green sinter bed greatly influence the heat transfer and flame front properties in the hot bed transformation stage, which are significant factors determining the final sinter productivity and quality, ${ }^{1-4)}$ more fundamental understanding of the cold bed preparation needs to

* Corresponding author: E-mail: zhouhao@zju.edu.cn DOI: http://dx.doi.org/10.2355/isijinternational.ISIJINT-2016-734 be targeted.

Historically magnetite concentrates in China have been used for sintering as well as pelletising. ${ }^{5)}$ However the expansion of lower cost iron ore fines production especially in Australia and Brazil during the last decade has led to a significant replacement of concentrates with fines in sinter blends in China. Nevertheless there are still several individual plants that still use significant levels of concentrate in the blend. However, more fine size of concentrates results in additional challenges for sintering such as the deterioration of the bed permeability typically. ${ }^{6}$ ) More research is required to understand the interaction between iron ore fines and concentrates and also binders during granulation to further improve sinter plant performance.

In iron ore sintering, various raw materials are generally subjected to granulation together in a rotary drum for several minutes with sprayed water acting as binder. The formed granules have a typical structure of a nucleus with an adhering fines layer. Previous studies showed that the properties of the ore feed determine the mechanisms oper- 
ating during granulation and influence granule properties remarkably. ${ }^{7-10)}$ The complex granulation process was well described and modeled by population balance. ${ }^{11-16)}$ A partition coefficient representing the probability for particles of a certain size to act as nuclei or adhering fines was proposed by Litster et al. ${ }^{11,12)}$ The established population balance model was first validated for single ore blend by predicting the Sauter mean diameter of granules. For a wider range of iron ores, the model was further validated by the studies of Waters et al., ${ }^{13)}$ Litster et al. ${ }^{14)}$ as well as Ekwebelam et $a l^{15)}$ Recently, Nyembwe et al. ${ }^{16)}$ investigated the feasibility of applying this model to ore blends that contain concentrate and micropellets and concluded that good agreement between the predicted and experimental values can be obtained.

Packing granules to form the green sinter bed is a wet packing process using multi-sized, deformable particles with irregular shapes. Previous studies reported that the parameters governing the packing process are granule density, inter-particle friction, size distribution as well as granule deformation. ${ }^{9,17,18)}$ Due to the complex interactions between the granulation and subsequent packing process, few successful models have been developed to predict the packed properties of green sinter bed including voidage and permeability. Khosa et al. ${ }^{10)}$ proposed an empirical model linking the optimum bed permeability to the iron ore chemical composition and size distribution. Their model showed acceptable predicted results for single ore blend rather than the mixed ore blends used in industrial practice. Venkataramana et al. $^{19)}$ developed a statistical model to predict bed voidage considering the spread of granule size distribution and feed specification parameters including $0.015 \mathrm{~mm}$ ultrafines, water content and lime content. Zhou et $a l .{ }^{20)}$ investigated the granule structure and packed bed properties of a mixed ore blend over a wide range of water and hydrated lime addition levels. A semi-empirical model predicting the bed voidage was developed taking the standard deviation of the granule size distribution, cohesive forces during packing and potential for granule deformation into consideration. Zhou et al. ${ }^{20)}$ illustrated that hydrated lime also acts as binder during granulation and can improve the packed bed permeability effectively. However, the ore blends tested did not contain magnetite concentrate. The influences of binder dosage on the improvement of bed permeability of blends that contain concentrate remain unclear and whether the developed voidage model is applicable for the blends containing concentrate needs further validation.

In the present paper, magnetite concentrate was introduced into a typical Asia-Pacific iron ore fines blend and its mass fraction was varied from $10 \%$ to $30 \%$. A total of 41 granulation experiments under a wide range of binder dosage conditions were performed to characterize the granule structure and packed bed properties of sinter blends that contain concentrate. Since the bed permeability is very sensitive to the bed voidage value, a more accurate prediction of bed voidage is helpful to the cold bed preparation of ore blending in industrial production. The previous semi-empirical green sinter bed voidage model by Zhou et $a l .{ }^{20)}$ was further modified based on the experimental results. Particular emphasis was given to considering how the characteristics of the produced granules such as their actual size distribution and potential of deformation affect the resulting bed voidage. The fit between model predictions and experimental measurements was improved.

\section{Experimental}

\subsection{Raw Materials and Sinter Mixtures}

Raw materials used in present study consisted of concentrate, iron ore fines, fluxes, coke, return fines and binder (hydrated lime). The size distribution of the raw materials were measured by a standard sieve shaker method and are available in previous work. ${ }^{20}$ ) The five iron ore fines have a quite wide spread size distribution ranging from $0 \mathrm{~mm}$ to $9 \mathrm{~mm}$. The fluxes including limestone, dolomite and serpentine are all crushed to $-3 \mathrm{~mm}$ while the size of coke and return fines are $-5 \mathrm{~mm}$. For the ultra-fines, including hydrated lime and concentrate, the size distribution was measured using a Coulter LS 230 laser particle analyzer, while their porosity was analyzed by mercury porosimetry (Auto Pore IV 9500). The results are given and compared in Table 1.

An ore blend consisting of five iron ore fines (16.7 wt $\%$ AUS1 fines, 16.7 wt $\%$ AUS2 fines, 33.3 wt $\%$ AUS3 fines, $16.7 \mathrm{wt} \%$ BRA1 fines, $16.7 \mathrm{wt} \%$ BRA2 fines) has been studied in previous work, ${ }^{20}$ which represents a typical blend used in the Asia-Pacific region and was treated as the base blend in present study. Magnetite concentrate was introduced into the base blend at levels of $10 \%$ and $30 \%$. Table 2 shows the ore blend details and the related flux proportions to target a typical chemistry of sintering operations $\left(\mathrm{TFe} \sim 56.5 \%, \mathrm{CaO} \sim 9.50 \%, \mathrm{SiO}_{2} 5.0 \%\right.$, basicity 1.90 , $\mathrm{Al}_{2} \mathrm{O}_{3} \sim 1.80 \%, \mathrm{MgO} \sim 1.70 \%$, return fines ratio $20 \%$, fuel rate $4.05 \%$ ). Each blend was studied under a wide range of binder levels, namely, the moisture content varied from $5 \%$ to $9 \%$ (wet basis) and the hydrated lime (HL) levels were controlled at $0 \%, 2 \%$ and $4 \%$ (dry total mix basis) respectively.

\subsection{Granulation}

Each sinter mixture weighing approximately $13.5 \mathrm{~kg}$ for a typical granulation condition was granulated in a cylindrical drum of diameter $500 \mathrm{~mm}$ and length $300 \mathrm{~mm}$. Agglomeration was continued for $10 \mathrm{~min}$ after spraying the desired amount of water with the drum rotating at 16 revolutions per minute. The Froude number and space factor of the granulation drum are 0.0036 and $11 \%$, respectively. After discharging, the granules were divided into several samples to measure the experimental moisture content and granule apparent density and to conduct the frozen granule size distribution and granule partitioning test. Details of the methods used are available in the open literature. ${ }^{9,17,20)}$

\subsection{Partition Curve Determination for Each Particle Size}

Partitioning tests were conducted immediately following the frozen granule size distribution procedure to measure the experimental partition curve based on the Litser's granulation model. Around $0.5 \mathrm{~kg}$ granules were frozen using liquid nitrogen and then sieved for $1 \mathrm{~min}$ into 13 size fractions, following a $\sqrt{2}$ series from $0.25 \mathrm{~mm}$ to $11.2 \mathrm{~mm}$. Granules of each size fraction were weighed and then dried at $105^{\circ} \mathrm{C}$ 
Table 1. Size and porosity measurement of hydrated lime and magnetite concentrate.

\begin{tabular}{cccc}
\hline & Item & Hydrated lime $^{20)}$ & Concentrate \\
\hline \multirow{2}{*}{$\begin{array}{c}\text { Size } \\
\text { measurement }\end{array}$} & $\begin{array}{c}\text { Mean volume } \\
\text { diameter }(\mu \mathrm{m})\end{array}$ & 12.7 & 92.3 \\
\cline { 2 - 4 } & Size distribution & $50 \%<14.26 \mu \mathrm{m}$ & $50 \%<83.89 \mu \mathrm{m}$ \\
& & $95 \%<22.73 \mu \mathrm{m}$ & $95 \%<213.2 \mu \mathrm{m}$ \\
\hline \multirow{5}{*}{$\begin{array}{c}\text { Potal intrusion } \\
\text { volume }(\mathrm{L} / \mathrm{g})\end{array}$} & 1.336 & 0.183 \\
\cline { 2 - 4 } measurement & $\begin{array}{c}\text { Average pore } \\
\text { diameter }(\mu \mathrm{m})\end{array}$ & 0.94 & 4.51 \\
\cline { 2 - 4 } & $\begin{array}{c}\text { Apparent } \\
\text { density }(\mathrm{g} / \mathrm{ml})\end{array}$ & 1.76 & 4.68 \\
\cline { 2 - 4 } & $\begin{array}{c}\text { Porosity }(\%) \\
0\end{array}$ & 70.1 & 46.2 \\
\hline
\end{tabular}

Table 2. Raw materials composition of the granule mix (mass $\%$ ).

\begin{tabular}{|c|c|c|c|c|c|c|}
\hline Blend & \multicolumn{2}{|c|}{$0 \% \mathrm{M}^{20)}$} & \multicolumn{2}{|c|}{$10 \% \mathrm{M}$} & \multicolumn{2}{|c|}{$30 \% \mathrm{M}$} \\
\hline Basis & $\begin{array}{c}\% \text { Dry } \\
\text { Ore } \\
\text { Basis }\end{array}$ & $\begin{array}{c}\% \text { Dry } \\
\text { Total } \\
\text { Basis }\end{array}$ & $\begin{array}{c}\% \text { Dry } \\
\text { Ore } \\
\text { Basis }\end{array}$ & $\begin{array}{c}\% \text { Dry } \\
\text { Total } \\
\text { Basis }\end{array}$ & $\begin{array}{c}\% \text { Dry } \\
\text { Ore } \\
\text { Basis }\end{array}$ & $\begin{array}{c}\% \text { Dry } \\
\text { Total } \\
\text { Basis }\end{array}$ \\
\hline AUS1 fines & 16.7 & & 15.0 & & 11.7 & \\
\hline AUS2 fines & 16.7 & & 15.0 & & 11.7 & \\
\hline AUS3 fines & 33.3 & & 30.0 & & 23.3 & \\
\hline BRA1 fines & 16.7 & & 15.0 & & 11.7 & \\
\hline BRA2 fines & 16.7 & & 15.0 & & 11.7 & \\
\hline Concentrate & 0.0 & & 10.0 & & 30.00 & \\
\hline $\begin{array}{l}\text { Sub-total } \\
\text { Iron ores }\end{array}$ & 100.0 & 62.0 & 100.0 & 61.3 & 100.0 & 60.8 \\
\hline Limestone & & 4.8 to 9.1 & & 5.4 to 9.8 & & 7.0 to 11.4 \\
\hline Serpentine & & 0.1 to 0.4 & & 0.7 to 1.0 & & 1.9 to 2.2 \\
\hline Dolomite & & 5.1 & & 4.2 & & 1.9 \\
\hline Coke & & 4.05 & & 4.05 & & 4.05 \\
\hline $\begin{array}{l}\text { Return } \\
\text { Fines }\end{array}$ & & 20 & & 20 & & 20 \\
\hline $\begin{array}{c}\text { Hydrated } \\
\text { lime }\end{array}$ & & $0,2,4$ & & $0,2,4$ & & $0,2,4$ \\
\hline
\end{tabular}

for 6 hours. After drying, each granule size fraction was manually wet screened at $63 \mu \mathrm{m}$ to separate the primary particles from the adhering fines. Then the $+63 \mu$ m portion particles were dried again and further sieved to determine the partition coefficient of each size fraction according to the following equation:

$$
\partial_{i}=\frac{m_{i i}+m_{i i+1}}{\sum_{j=1}^{n} m_{i j}}
$$

Where $m_{i j}$ is the mass of particles of size fraction $i$ found in particles of size fraction $\mathrm{j}$.

After granulation, it is assumed that particles of $i$ th size fraction which act as nuclei will appear in the screens of both $i$ th and $(i+1)$ th. A partition coefficient of 1 means the particles of size fraction $i$ all act as nuclei during granulation while a value of 0 means all act as adhering fines. The parti-

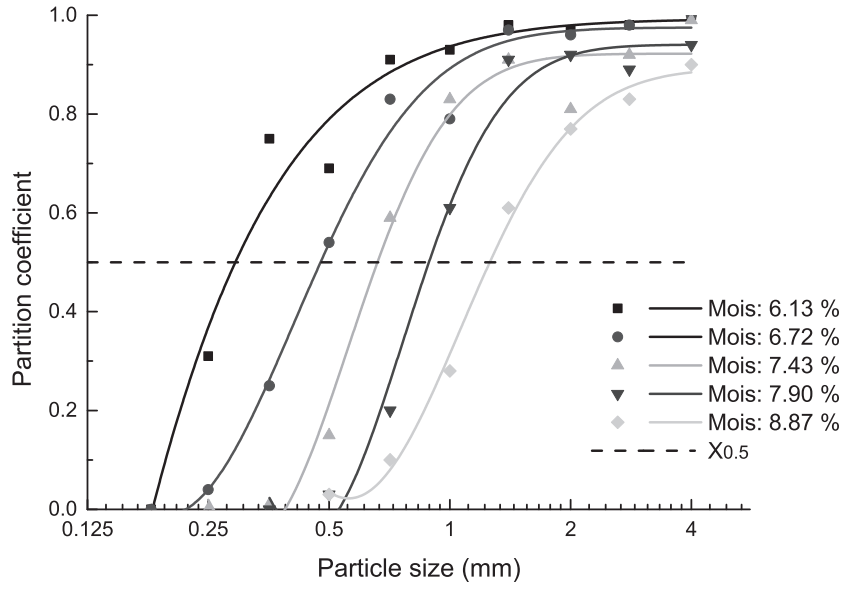

Fig. 1. Determination of $\mathrm{X}_{0.5}$ from partition coefficient curves (30\% M 2\% HL blend under different moisture content conditions).

tion coefficients for $30 \%$ M $2 \%$ HL blend under different moisture conditions are shown in Fig. 1. There are a number of size fractions where some particles act as nuclei and the rest act as adhering particles, i.e., $\partial$ is between 0 and 1 . For a blend with so many concentrate particles, it can be seen that even some $+1 \mathrm{~mm}$ particles would also act as adhering particles when the granulation moisture is high.

Fitting the experimental partition coefficient curves in Fig. 1 to a log-normal function, the $\mathrm{X}_{0.5}$ parameter which has a partition coefficient value of 0.5 and represents the effectiveness of the granulation process could be determined. The adhering mass ratio of granules could also be calculated by mass balance of all size fractions..$^{9,11-16,20)}$

\subsection{Permeability Pot Packing Tests}

Around $10 \mathrm{~kg}$ granules were charged into a permeability pot via a loading device positioned above the pot. This random packing procedure is described specifically in previous work. ${ }^{20)}$ The green bed voidage in the permeability pot with a diameter of $100 \mathrm{~mm}$ and the height of $600 \mathrm{~mm}$ is calculated as:

$$
\varepsilon=1-\frac{\rho_{\text {bulk }}}{\rho_{\text {apparent }}}
$$

Where $\varepsilon$ is the green bed voidage, $\rho_{\text {bulk }}$ is the bulk density of granules in the permeability pot $\left(\mathrm{kg} / \mathrm{m}^{3}\right), \rho_{\text {apparent }}$ is the apparent density of granules measured by the kerosene displacement method $\left(\mathrm{kg} / \mathrm{m}^{3}\right)$.

Compressed air was forced to pass through the green bed and the airflow rate was adjusted to keep the pressure drop across the $500 \mathrm{~mm}$ bed at $4 \mathrm{kPa}$ and $6 \mathrm{kPa}$ respectively. The mean value of the measured airflow rate from two repeat packing tests was converted to Japanese Permeability Units (JPU) to quantify the green bed permeability according to the equation below.

$$
\mathrm{JPU}=\frac{\mathrm{Q}}{\mathrm{A}}\left(\frac{\mathrm{H}}{\Delta \mathrm{P}}\right)^{0.6}
$$

Where $\mathrm{Q}$ is the air flow rate through the green bed $\left(\mathrm{m}^{3} / \mathrm{min}\right), \mathrm{H}$ and $\mathrm{A}$ are the bed height and bed cross sectional area respectively $\left(\mathrm{mm}, \mathrm{m}^{2}\right), \Delta \mathrm{P}$ is the pressure drop along the green bed $\left(\mathrm{mm} \mathrm{H}_{2} \mathrm{O}\right)$. 


\section{Results}

\subsection{Granule Properties}

The Sauter mean diameter $d_{p}$ (SMD) calculated from the size distribution of granules was used to quantify the size enlargement of raw materials as:

$$
d_{p}=\frac{1}{\sum_{i} \frac{x_{i}}{\bar{d}_{i}}}
$$

Where $\bar{d}_{i}$ is the mean size of size interval i, $x_{i}$ is the mass percent of granules in size interval $i$.

Figure 2 plots the Sauter mean diameter of granules versus moisture content while the spread of granule size distribution is shown in Fig. 3. The solid line, dash line and dash-dot-dot line fitted by least-square method in Fig. 2 stand for the base blend, 10\% $\mathrm{M}$ blend and 30\% $\mathrm{M}$ blend respectively. The hydrated lime addition levels of $0 \%, 2 \%$ and $4 \%$ are labeled in black, red and blue respectively (the legend is the same for the following figures if needed). For the blends containing concentrate, the SMD of granules increases linearly with increasing moisture content. ${ }^{9}{ }^{20)}$ The steeper slopes for $10 \% \mathrm{M}$ blend and $30 \% \mathrm{M}$ blend at the same HL addition level suggest that the concentrate addition decreased the granule mean size when the moisture was low and increased the granule mean size when moisture was high. The spread of granule size distribution becomes narrower with the increase of moisture. The log-normal deviation of granule size distribution decreases from 1.0 at $5 \mathrm{wt} \%$ $\mathrm{H}_{2} \mathrm{O}$ to 0.65 at $9 \mathrm{wt} \% \mathrm{H}_{2} \mathrm{O}$ as shown in Fig. 3 .

Both the concentrate and HL are ultra-fine particles below $0.25 \mathrm{~mm}$, which would all act as adhering particles during granulation. Figure 4 illustrates the granulation efficiency parameter $\mathrm{X}_{0.5}$ of different blends. It can be seen from Fig. 4 that an increase in the proportion of ultra-fine particles in the blend, no matter whether the particles are cohesive HL particles or less cohesive concentrate particles, leads to a steeper fitted line, suggesting higher granulation efficiency. For the $30 \% \mathrm{M}$ blend with $4 \% \mathrm{HL}$ addition level, the cut-off size between the nuclei and adhering particles can be as large as $1.2 \mathrm{~mm}$. It is widely acknowledged that the granulation process in sintering happens through a two-stage mechanism. The ultra-fine particles adhere onto the nuclei particle first and form an initial inner layer, allowing some intermediate particles to be incorporated and producing bigger granules. ${ }^{9,13-17)}$ Therefore, if the added moisture is sufficient to form liquid bridges between the particles, the existence of more $-0.25 \mathrm{~mm}$ particles would favour the extent of nucleation and coalescence during granulation, resulting in a larger granule mean size with a more pellet-like structure. ${ }^{16)}$

\subsection{Green Bed Properties}

Green bed voidage data for all blends is illustrated as a function of moisture content in Fig. 5. It can be seen from the voidage-moisture curves that the blends with more concentrate have much lower bed voidage at higher moisture content state. Hinkley et al. ${ }^{17)}$ reported that the deformation of the adhering layer is the key mechanism determining the green bed voidage and fitted the following relationship between voidage and adhering mass ratio:

$$
\varepsilon=\varepsilon^{*}+a \exp (-\mathrm{R})
$$

Where $a$ is a fitted parameter, $\mathrm{R}$ is the adhering mass to nuclei mass ratio, $\varepsilon^{*}$ is the green bed voidage for granule minipellets without nuclei particles, i.e. when $\mathrm{R}$ approaches infinity.

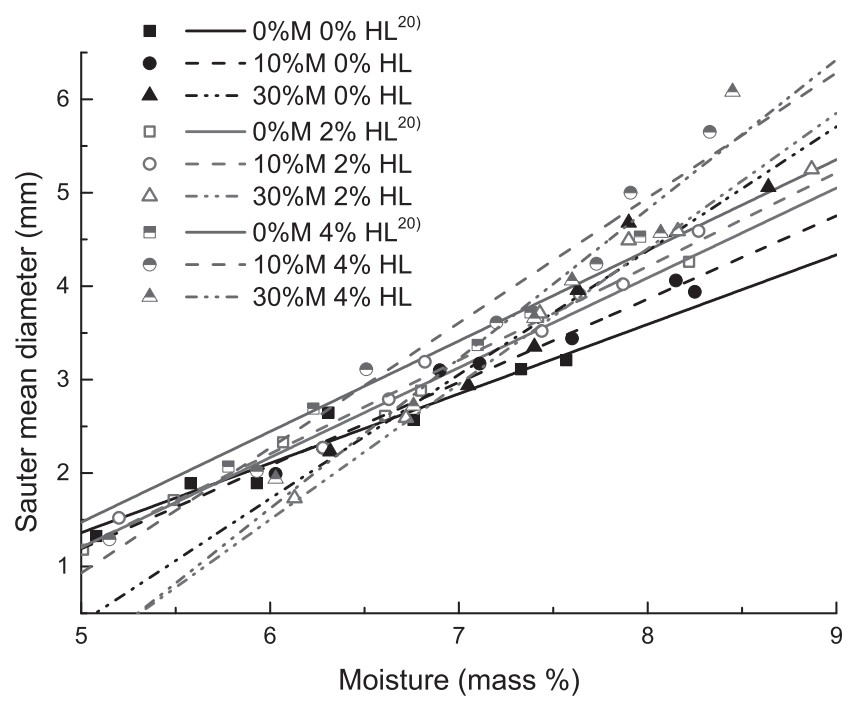

Fig. 2. Sauter mean diameter of granules versus moisture content.

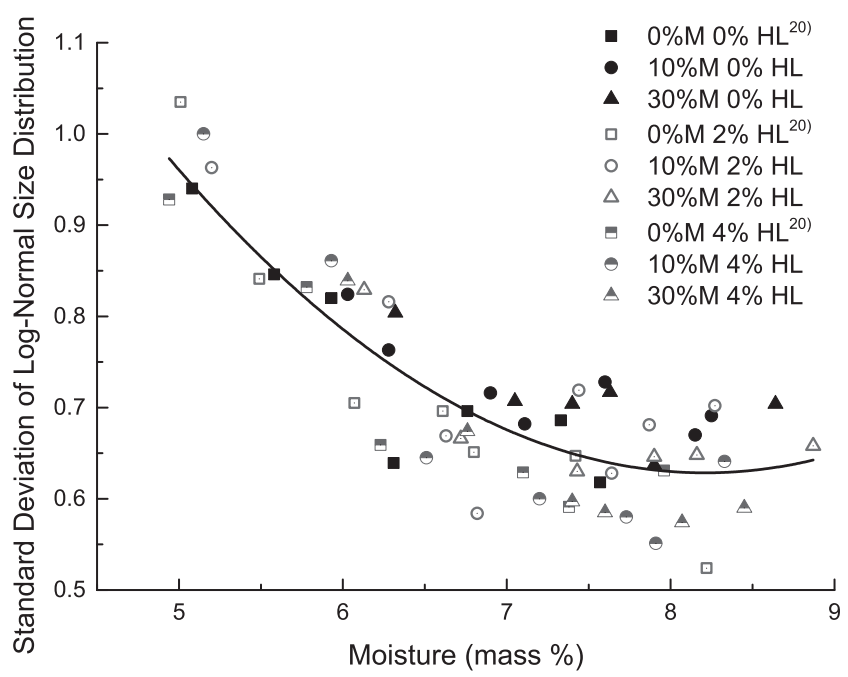

Fig. 3. Deviation of log-normal size distribution versus moisture content.

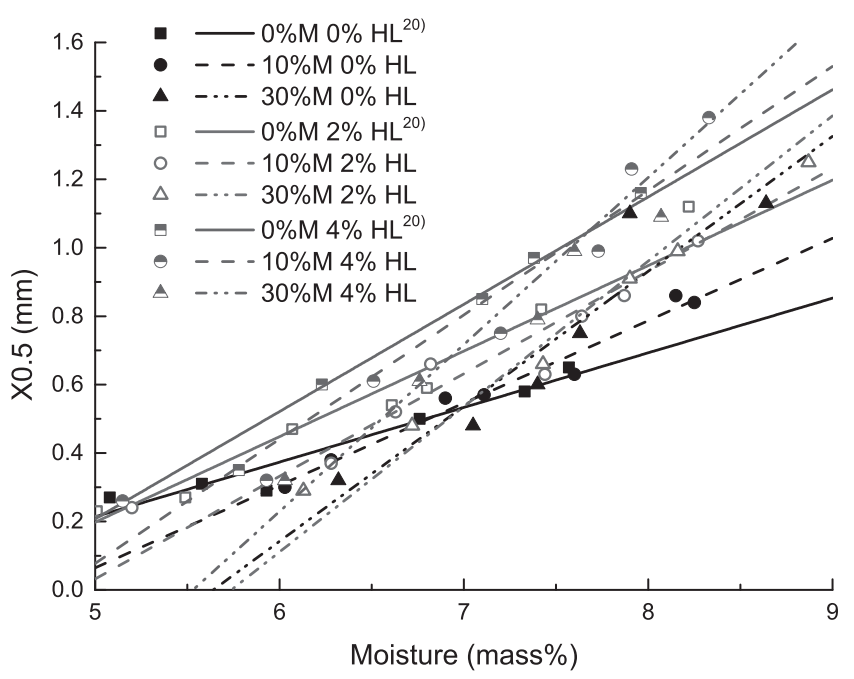

Fig. 4. $\mathrm{X}_{0.5}$ versus moisture content. 
Figure 6 depicts the relationship between the voidage and adhering mass ratio of different blends. Hinkley et $a l .{ }^{17)}$ tested several ore blends without concentrate and solid binder, they got the best fitted constants of $a=0.072$ and $\varepsilon^{*}=0.341$ of Eq. (5), which is also plotted in Fig. 6 and compared with results of blends containing concentration. Introducing more concentrate into the base blend causes the adhering mass ratio to increase at the same moisture content, which means a thicker adhering layer is formed. For the $10 \% \mathrm{M}$ blend and $30 \% \mathrm{M}$ blend, the green bed voidage decreases more rapidly with the increase of adhering mass ratio as the hydrated lime level is decreased. This changing trend confirms that the adhering layer strength becomes weaker when more concentrate particles exist in blend. Compared to the base blend, the effect of HL to increase the adhering layer strength in the $30 \% \mathrm{M}$ blend is much smaller.

Bergstrand et $a l^{21)}$ reported that the initial inner layer characteristics, controlled by the mineralogical and textural properties of $-50 \mu \mathrm{m}$ particles, are especially important for granulation behavior. The interaction and distribution of micro particles including concentrate and hydrated lime generate the initial matrix for intermediate sized particles to embed in. Figure 7 shows the surface properties of the concentrate and hydrated lime observed by SEM. Compared to the hydrated lime, the surface of concentrate particles is much smoother and is therefore not as able to be bonded tightly by liquid bridges. The concentrate particles also have

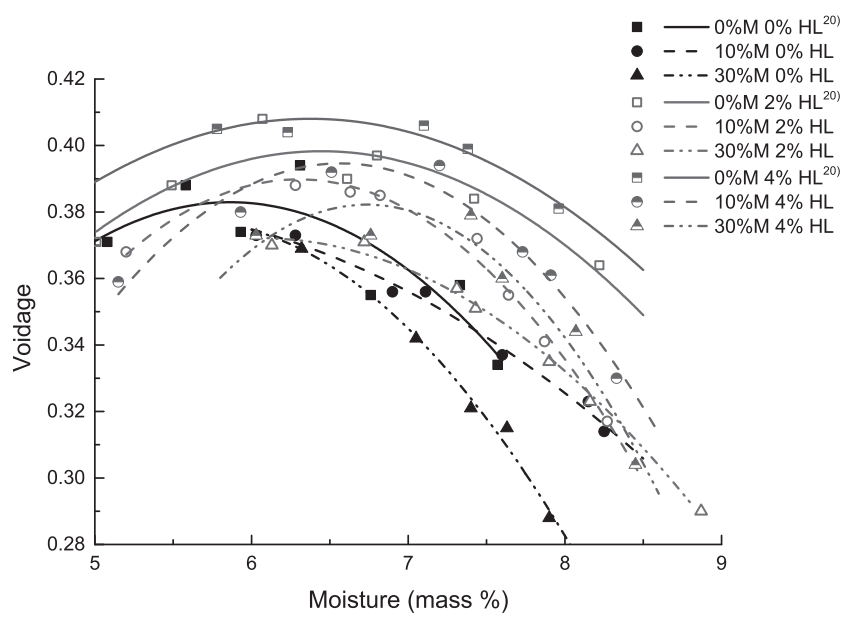

Fig. 5. Bed voidage versus moisture content.

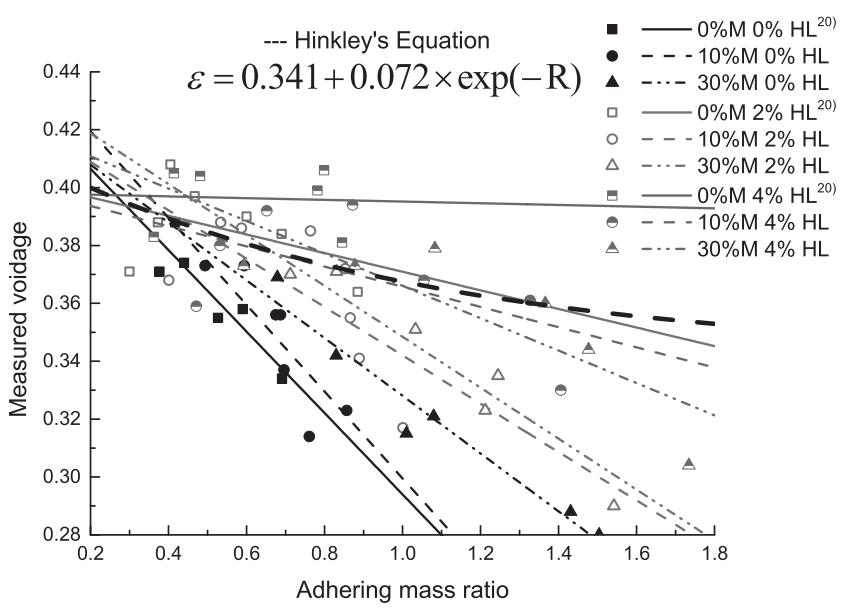

Fig. 6. Bed voidage versus adhering mass ratio. a much larger particle size and higher density than hydrated lime (see Section 2.1), providing less contact/bridge points between granulating particles and therefore lead to a thicker and weaker adhering layer.

Figure 8 shows the green bed permeability of all blends

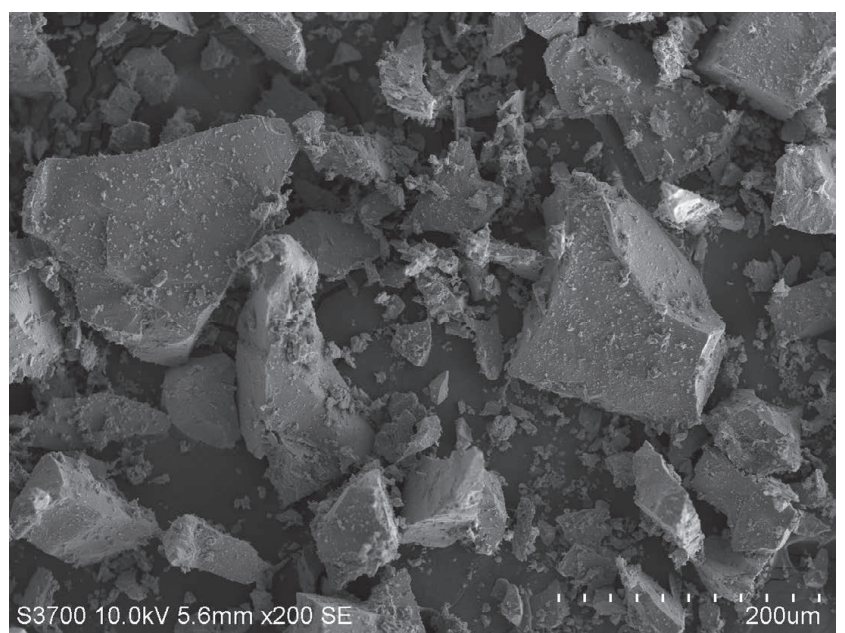

(a) Magnetite concentrate

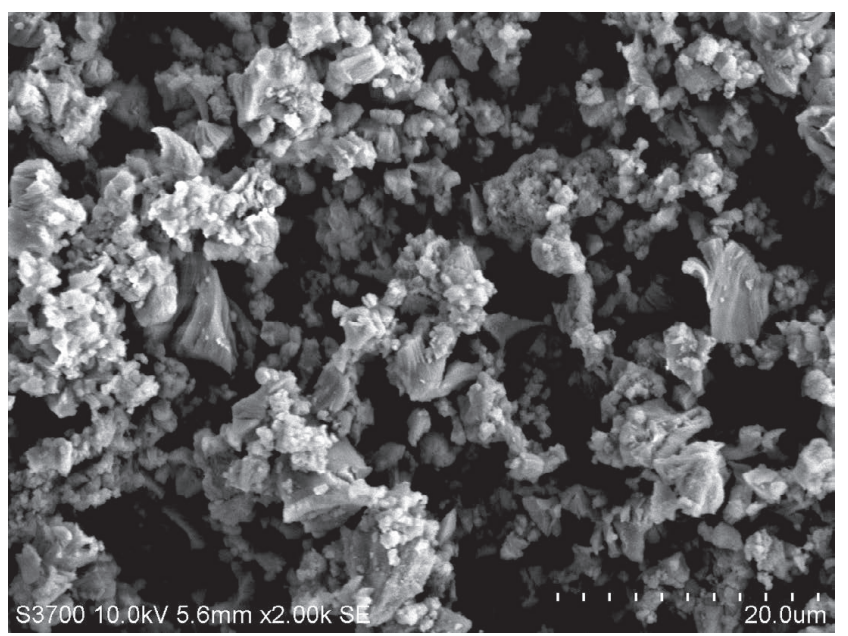

(b) Hydrated lime

Fig. 7. SEM pictures of the magnetite concentrate and the hydrated lime particles.

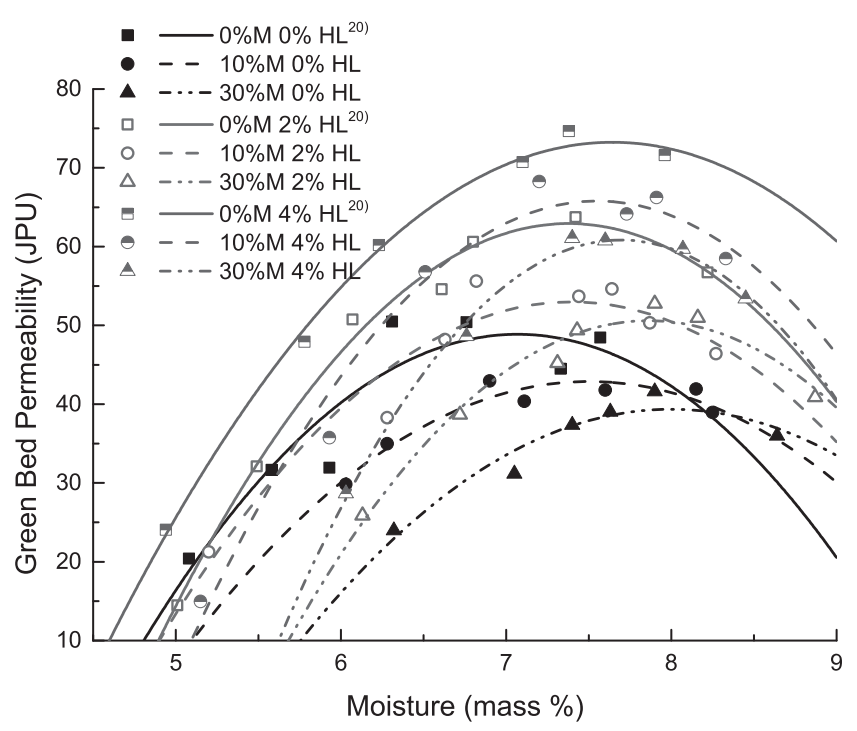

Fig. 8. Green bed permeability (JPU index) verse moisture content. 
as a function of moisture content. All data follow a similar parabolic trend. The optimum JPU values derived from the curves in Fig. 8 were further plotted versus the concentrate level and hydrated lime level respectively, as shown in Fig. 9. It is clear to see that blending more concentrate decreases the optimum JPU whereas increasing HL binder could improve the optimum JPU. For the tested 10\% M blend and $30 \% \mathrm{M}$ blend, increasing HL from $0 \mathrm{wt} \%$ to $4 \mathrm{wt} \%$ could improve the green bed permeability from 53.0 to 65.8 and 39.4 to 60.8 respectively.

The Ergun equation has been widely accepted to explain the relationship between pressure drop and particle characteristics for a particle packed bed.

$$
\frac{\Delta P}{L}=k_{1} \frac{\mu(1-\varepsilon)^{2}}{\Phi^{2} d_{p}^{2} \varepsilon^{3}} U+k_{2} \frac{\rho(1-\varepsilon)}{\Phi d_{p} \varepsilon^{3}} U^{2}
$$

Where $\Delta P$ is the bed pressure drop (pa), L is the bed height (m), $\mu$ and $\rho$ are the gas viscosity and density respectively $\left(\mathrm{pa} / \mathrm{s}, \mathrm{kg} / \mathrm{m}^{3}\right), k_{1}$ and $k_{2}$ are the viscous and inertial resistance coefficients, $\Phi$ is the particle sphericity, and $d_{p}$ is surface/volume mean size of particles (m), and $U$ is the superficial gas velocity $(\mathrm{m} / \mathrm{s})$.

The optimum parameters when the green bed permeability reaches a maximum value for each blend are summarized in Table 3. For the blends containing concentrate, although the SMD increases with increasing moisture, the decreas-

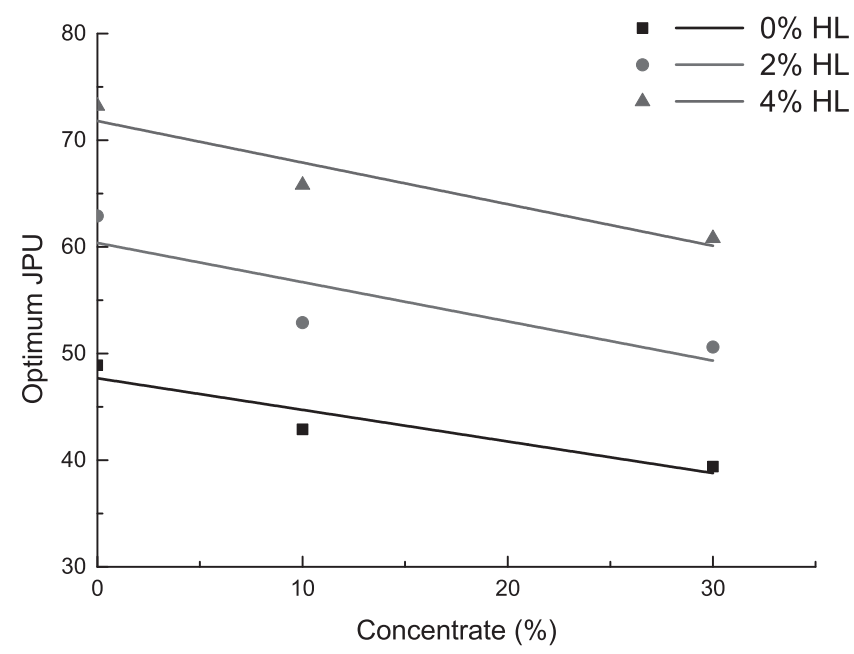

Fig. 9. The optimum JPU values versus concentrate level hydrated lime level.

Table 3. Optimum parameters at the maximum bed permeability for each blend.

\begin{tabular}{cccccccccccc}
\hline Blend & \multicolumn{3}{c}{$0 \% \mathrm{M}^{20}$} & \multicolumn{5}{c}{$10 \% \mathrm{M}$} & \multicolumn{5}{c}{$30 \% \mathrm{M}$} \\
\hline $\begin{array}{c}\mathrm{HL} \\
\text { addition } \\
\text { level/\% }\end{array}$ & 0 & 2 & 4 & 0 & 2 & 4 & 0 & 2 & 4 \\
$\begin{array}{c}\text { Optimum } \\
\text { moisture/\% }\end{array}$ & 7.06 & 7.39 & 7.64 & 7.51 & 7.39 & 7.55 & 8.00 & 7.86 & 7.55 \\
$\begin{array}{c}\text { Optimum } \\
\text { SMD/mm }\end{array}$ & 2.90 & 3.50 & 4.04 & 3.40 & 3.60 & 4.34 & 4.39 & 4.20 & 4.11 \\
$\begin{array}{c}\text { Optimum } \\
\text { Deviation }\end{array}$ & 0.656 & 0.591 & 0.610 & 0.690 & 0.652 & 0.581 & 0.683 & 0.624 & 0.588 \\
$\begin{array}{c}\text { Optimum } \\
\text { bed } \\
\text { voidage }\end{array}$ & 0.360 & 0.388 & 0.392 & 0.342 & 0.368 & 0.376 & 0.283 & 0.338 & 0.366 \\
\hline
\end{tabular}

ing bed voidage limits the increase in bed permeability. For the $0 \% \mathrm{M}$ blend, when the HL addition level increases, the optimum moisture corresponding to the optimum bed permeability increases since a larger granule size and greater bed voidage can be obtained with higher moisture content. However, for the blend with $30 \%$ magnetite, the optimum bed permeability occurs in the region where the granules have a smaller particle size but bigger bed voidage. Too much magnetite concentrate in the sinter blend is not favorable for granule packing and additional granulation methods such as addition of burnt lime and pre-granulation are needed to maintain the bed permeability. ${ }^{5}$

\section{Discussions}

\subsection{Previous Green Bed Voidage Model}

Since the bed voidage is a critical parameter determining the green bed permeability and flame front speed during sintering, it is important to predict the voidage value precisely for modeling the sintering process and optimizing the actual plant production. A semi-empirical model was developed by Zhou et $a{ }^{20)}$ recently to predict the green bed voidage considering the deviation of granule size distribution, cohesive forces during packing and potential for granule deformation.

$$
\begin{array}{r}
\varepsilon=\varepsilon_{0}+\left(1-\varepsilon_{0}\right) \exp \left(-m R^{-n}\right) \\
\varepsilon_{0}=0.36 \times\left(e^{\sigma}\right)^{-0.3209} \ldots \ldots
\end{array}
$$

Where $\varepsilon_{0}$ is the ideal voidage formed by dry coarse nondeformable particles, $\mathrm{m}$ and $\mathrm{n}$ are fitted parameters, $\sigma$ is the lognormal standard deviation of the granule size distribution.

Packing results of the single ore blends in the literature, ${ }^{9)}$ base blend in the literature ${ }^{20)}$ and blends with concentrate in the present paper were fitted by the equations above, giving the best fitted parameters of $m=2.522$ and $n=-0.281$. The comparison between the predicted voidage values and the experimental values are shown in Fig. 10. Most of the data is located in the $\pm 10 \%$ error zone, however, the predicted voidage values seem to be flat compared to the measured voidage, suggesting that the model can be improved.

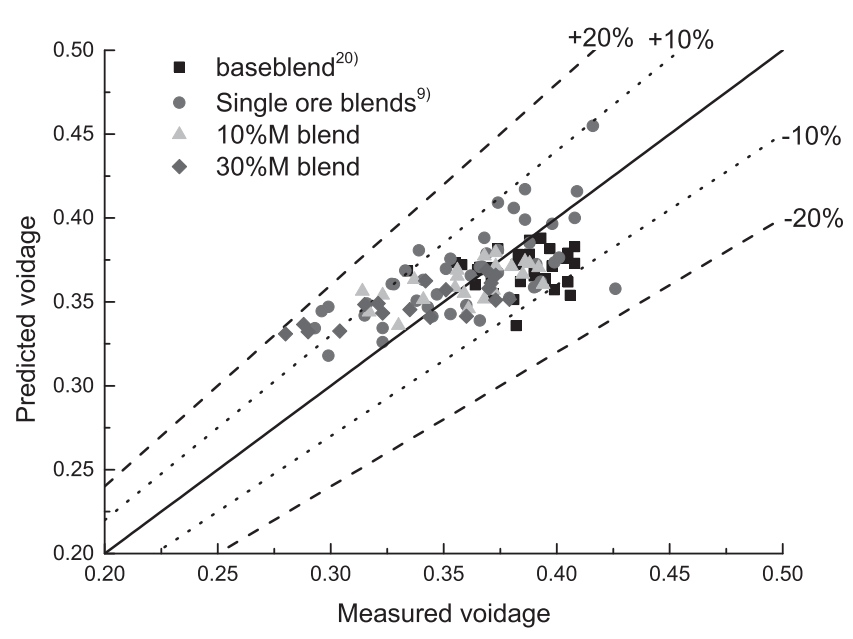

Fig. 10. Comparison of model predicted and measured bed voidage of the previous model in the literature. ${ }^{20)}$ 


\subsection{1-Dimensional Packing Algorithm}

In Zhou's voidage model, the ideal porosity $\varepsilon_{0}$ was calculated by Eq. (8), which was developed by Brouwers for predicting voidage of dry coarse particles with a log-normal size distribution. ${ }^{22,23)}$ It needs to be mentioned that the wet iron ore granules do not strictly follow a log-normal distribution, so simply using the log-normal deviation parameter rather than the actual size distribution data would definitely cause some inaccuracy. Farr et al. ${ }^{24,25)}$ developed a one-dimensional mapping algorithm for predicting random close packing fractions of polydisperse hard spheres, which is easy to implement and can give acceptable results in several seconds compared to more complex and time consuming DEM simulations.

The 1-dimensional packing algorithm begins with the construction of a distribution $P_{1 D}(\mathrm{~L})$ of rod lengths mapped from the a number-weighted diameter distribution $P_{3 D}(\mathrm{D})$, as shown in Fig. 11. The rods with lengths $\left\{L_{i}\right\}$ drawn from the 1-D distribution $P_{1 D}(\mathrm{~L})$ are placed on a line sequentially in decreasing order. Through the rod packing process, a set of gaps $\left\{g_{i}\right\}$ is introduced and its number is equal to the number of rods. The gap between any pair of rods is defined to be at least a proportion $f$ of the shorter of the pair. When inserting rod $j$, the largest gap $\left\{g_{\max }\right\}$ is identified and removed from the set, then two new gaps of $f L_{j}$ and max

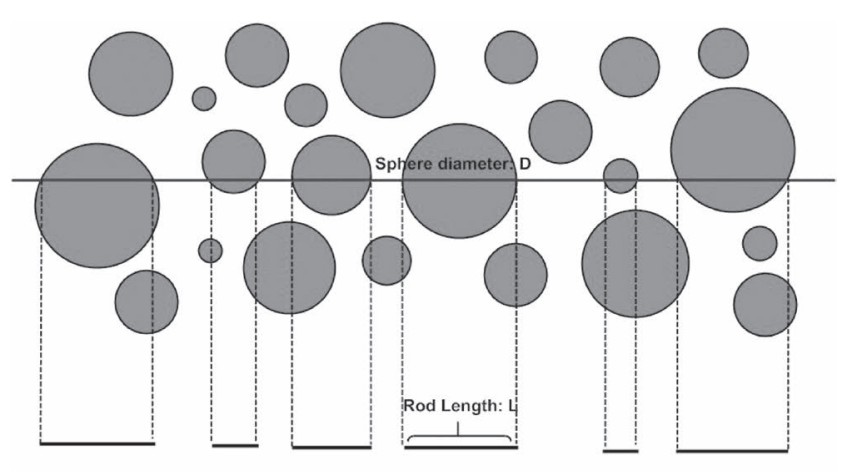

The probability of mapping a 3-D sphere distribution into a 1-D distribution:

$$
P_{1 D}(\mathrm{~L})=2 L \frac{\int_{L}^{\infty} P_{3 D}(\mathrm{D}) \mathrm{dD}}{\int_{0}^{\infty} P_{3 D}(\mathrm{D}) \cdot \mathrm{D}^{2} d D}
$$

Fig. 11. Schematic diagram of the mapping of a 3-D sphere distribution onto a 1-D rod distribution. ${ }^{24,25)}$

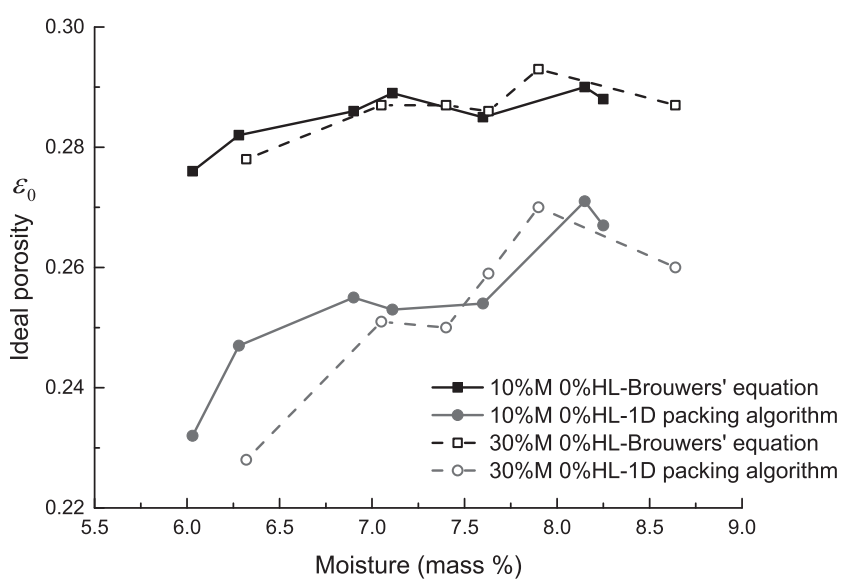

Fig. 12. Comparison of the predicted ideal voidage values of the Brouway's equation and 1D packing algorithm. $\left[g_{\max }-(1+f) L_{j}, f L_{j}\right]$ are added to the set of gaps. Finally, a great number of rods are arranged on a line with the length of $\Lambda$ and the porosity is determined to be $\frac{\sum L_{i}}{\Lambda} \cdot{ }^{24,25)}$ In present study, the number of rods is set to be 100000 , which is sufficient for getting accuracy results. The only parameter, $f$, used in the $1 \mathrm{D}$ packing algorithm was fixed to 0.8312 to get a packing porosity of 0.376 for monosized particles, corresponding to a sphericity of 0.86 which is similar to sand. ${ }^{23)}$

Figure 12 shows the comparison of the ideal porosity values predicted by Brouwers' equation and the 1D packing algorithm, respectively. Whatever the blend is, the predicted ideal porosity $\varepsilon_{0}$ by the $1 \mathrm{D}$ packing algorithm is smaller than the predicted value by Brouwers' equation, especially in the low moisture content state where the agglomeration of raw materials happens little during granulation. The granule size distribution spreads so wide that more small particles can move in the void between the large particles when using actual size distribution data rather than the simple deviation parameter. For the $30 \% \mathrm{M}$ blend, the larger proportion of $-0.25 \mathrm{~mm}$ particles compared to the $10 \% \mathrm{M}$ blend results in a much smaller ideal porosity when granulation moisture is low.

\subsection{Improvement of the Green Bed Voidage Model}

For ore blends containing much concentrate, when granulation moisture is low, the agglomeration happens little therefore there are still a large proportion of $-0.25 \mathrm{~mm}$ particles in the produced granules. However, when the granulation moisture is high, the higher growth rate of granule leads to a much thicker and deformable granule adhering layer, forming a lower bed voidage during packing. To get a more accurate value of the ideal porosity of dry nondeformable particles, the 1D packing algorithm was used to replace Eq. (8) to predict the ideal porosity based on the actual granule size distribution data of 13 size intervals measured by the standard sieve shaker method. In addition, it is expected that only the adhering layer of granules deform during packing, not the nuclei particles. A thicker adhering layer increases the probability of deformation occurring. In particular, a thicker adhering layer at high moisture contents contains more intermediate size particles on the outside surface of the granules. Once deformation occurs, these intermediate particles are much easier to be broken from the adhering layer and flow into the void between the granules. Therefore, a nondimensional parameter $a\left(1-X_{0.5} / d_{p}\right)$ representing the probability of deformation occurring in the adhering layer was added to the second term of Eq. (7), resulting in Eq. (9) below.

$$
\varepsilon=\varepsilon_{0}+a\left(1-X_{0.5} / d_{p}\right)\left(1-\varepsilon_{0}\right) \exp \left(-m R^{-n}\right)
$$

All the granulation and packing data including single blends, ${ }^{9}$ base blend, ${ }^{20)}$ 10\% M blend and 30\% M blend were input to the improved green bed voidage model, resulting in the best fitted parameters of $m=1.004, n=-1.393$ and $\mathrm{a}=0.328$. The measured voidage and predicted voidage of all granulation conditions are compared in Fig. 13. It can be seen that by using the $1 \mathrm{D}$ packing algorithm and the modified deformation term, the predicted voidage is not so flat compared to the previous model. The correlation coefficient increases from 0.60 to 0.67 , demonstrating that more accu- 


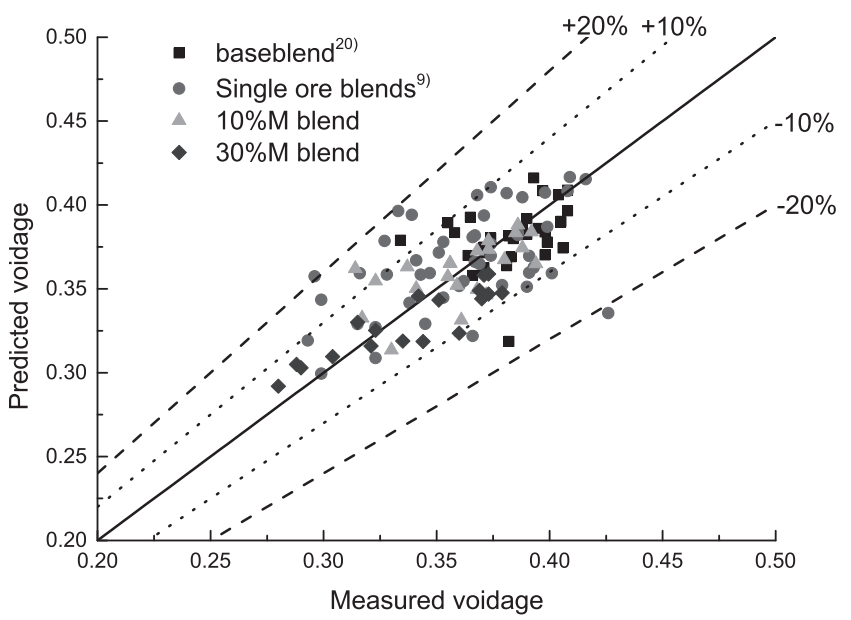

Fig. 13. Comparison of model predicted and measured bed voidage of the improved model.

rate predicted results can be obtained. Besides, the improved voidage model seems to be more applicable to the mixed blends rather than the single ore blends, showing its ability to be used for actual production.

\section{Conclusion}

The granulation and packing experiments carried out with different levels of magnetite concentrate added into a typical Asia-Pacific ore blend shows that:

The granule Sauter mean diameter is linked proportionally to the increasing moisture content, and the introduction of magnetite concentrate resulted in a higher granule growth rate and larger adhering mass ratio of granules.

However, the introduction of magnetite concentrate into the sinter blend is not good for the green bed permeability. With the addition of magnetite concentrate, the green bed voidage decreases markedly during packing due to the deformation of the thicker and weaker adhering layer. Compared to ore blends without concentrate, the optimum bed permeability of blends containing concentrate would be obtained in the region where the Sauter mean diameter is smaller and the bed voidage is larger. Adding solid binder such as hydrated lime could improve the bed permeability effectively for all blends tested.

Two improvements were proposed to the semi-empirical voidage model: one is replacing the previous packing correlation of strictly log-normal distributed particles with a 1 dimensional packing algorithm based on the actual size distribution; the other is adding a non-dimensional term
$a\left(1-X_{0.5} / d_{p}\right)$ to constrain the deformation to occur to adhering layer only. The improved green bed voidage model was validated using data covering single ore blends, the base blend as well as blends with concentrate addition and the predicted results were better than the previous model. By applying the improved green bed voidage model in conjunction with the granulation model developed by Litster, bed voidage can be predicted more accurately from the properties of the raw materials in sinter feed and granulation moisture, which is valuable for modeling the sintering process and optimizing production.

\section{Acknowledgment}

Financial support for this work has been provided by BHP Billiton and this is gratefully acknowledged. Financial support from National Natural Science Foundation of China (51476137) for Prof. Zhou is also gratefully acknowledged.

\section{REFERENCES}

1) C. E. Loo and M. F. Hutchens: ISIJ Int., 43 (2003), 630.

2) H. Zhou, J. P. Zhao, C. E. Loo, B. G. Eills and K. F. Cen: ISIJ Int., 52 (2012), 2168

3) H. Zhou, M. X. Zhou, Z. H. Liu, M. Cheng, K. Z. Qiu and K. F. Cen: ISIJ Int., 55 (2015), 2556.

4) H. Zhou, M. X. Zhou, Z. H. Liu, M. Cheng and J. Z. Chen: Fuel, 179 (2016), 922.

5) L. X. Yang and D. Witchard: ISIJ Int., 38 (1998), 1069.

6) A. M. Nyembwe, R. Cromarty and A. M. Garbers-Craig: Trans. Inst. Min. Metall. C, 125 (2016), 178

7) S. M. Iveson, J. D. Litster, K. Hapgood and B. J. Ennis: Powder Technol., 117 (2001), 3.

8) A. Formoso, A. Moro, G. Fernandez Pello, J. L. Menendez, M. Muniz and A. Cores: Ironmaking Steelmaking, 30 (2003), 447.

9) B. G. Ellis, C. E. Loo and D. Witchard: Ironmaking Steelmaking, 34 (2007), 99.

10) J. Khosa and J. Manuel: ISIJ Int., 47 (2007), 965.

11) J. D. Lister, A. G. Waters and S. K. A. Nicol: Trans. Iron Steel Inst. Jpn., 26 (1986), 1036.

12) J. D. Lister and A. G. Waters: Chemica, 86 (1986), 72.

13) A. G. Waters, J. D. Litster and S. K. Nicol: ISIJ Int., 29 (1989), 274.

14) J. D. Litster and A. G. Waters: Powder Technol., 62 (1990), 125.

$15)$ C. C. Ekwebelam, B. G. Ellis and T. A. G. Langrish: Asia-Pacific J. Chem. Eng., 2 (2007), 137.

16) A. M. Nyembwe, R. D. Cromarty and A. M. Garbers-Craig: Powder Technol., 295 (2016), 7.

17) J. Hinkley, A. G. Waters, D. O. Dea and J. D. Litster: Int. J. Miner. Process. 41 (1994), 53.

18) J. Q. Xu, R. P. Zou and A. B. Yu: Powder Technol., 169 (2006), 99.

19) R. Venkataramana, S. S. Gupta and P. C. Kapur: Int. J. Miner. Process., 57 (1999), 43.

20) H. Zhou, M. X. Zhou, D. O. Dea, B. G. Ellis, J. Z. Chen and M. Cheng: ISIJ Int., 56 (2016), 1920.

21) R. Bergstrand, J. Khosa, A. Waters and J. Garden: ISIJ Int., 45 (2005), 492.

22) H. J. H. Brouwers: Phys. Rev. E, 74 (2006), 031309.

23) H. J. H. Brouwers: Phys. Rev. E, 89 (2014), 052211

24) R. S. Farr and R. D. Groot: J. Chem. Phys., 131 (2009), 244104.

25) R. S. Farr: Powder Technol., 245 (2013), 28. 